\title{
Plastic Deformation in B.C.C. Alloys Induced by Hydrogen Concentration Gradients
}

\author{
M. E. ARMACANQUI and R. A. ORIANI \\ The Corrosion Research Center, and Department of Chemical Engineering and Materials Science, University of \\ Minnesota, Minneapolis, MN 55455 (U.S.A.)
}

(Received July 11, 1986; in revised form September 15, 1986)

\section{ABSTRAC'T}

Electrolytic charging of hydrogen into one side of polycrystalline b.c.c. Ti-30Mo plates (where the composition is given in approximate weight per cent) is found to generate dislocations at which the hydrogen atoms are trapped during their diffusion across the metal thickness. The defect generation is a result of stresses arising from the hydrogen concentration gradient at the entry surface. The generation of dislocations occurs on initiating the charging and persists thereafter with emission of dislocations towards the far side of the plate. As a consequence, slip lines and subgrains are formed at the entry and far sides. Also a non-homogeneous dislocation distribution and a piling-up at the grain boundaries occur. The slip line density is found to increase with the charging current density and time of charging. Prolonged charging causes spontaneous fracture and plastic bending in the absence of external forces. Similar phenomena have been detected also in tantalum and niobium.

\section{INTRODUCTION}

Preliminary work [1] with some b.c.c. metals showed that hydrogen charging from unpoisoned acid solution can produce kinetics of lattice parameter change that are highly anomalous with respect to diffusion-controlled kinetics. These results suggested that the charging produced defects which acted as traps for hydrogen atoms and slowed down their diffusion. The cause of defect generation by hydrogen charging was thought to be the hydrogen concentration gradient below the entry surface. Studies by others of solute diffusion in various metals have also indicated that dislocations are generated during diffusion to relax stresses [2-5].

In substitutional diffusion, dislocations are produced by the plastic deformation associated with the Kirkendall effect. The diffusion of the larger interstitial solutes has been shown also to induce dislocation generation $[6,7]$. Heusler and coworkers [8] have reported dislocation generation in iron subjected to cathodic charging. However, it is known that, in iron cathodically charged at high fugacities, large mechanical stresses and hence plastic deformation can be generated by the large gas pressures produced by the reassociation of dissolved hydrogen within microvoids [9$12]$, and even cracking can result $[13,14]$. The present work gives evidence that dislocation generation in b.c.c. metals can result from hydrogen charging in the absence of the formation of molecular hydrogen.

\section{EXPERIMENTAL PROCEDURE}

Metal plates, about $0.5 \mathrm{~mm}$ thick and 8.6 $\mathrm{mm}$ in diameter, of annealed polycrystalline Ti-30Mo (which in fact contained $70 \mathrm{wt} . \% \mathrm{Ti}$ and $29.59 \mathrm{wt} . \% \mathrm{Mo}$ ), tantalum and niobium were cathodically charged with hydrogen from one side (to be called the entry side) while the other side (to be called the far side) was dry and was subjected to X-ray diffraction. The niobium and tantalum samples, with a purity of at least $99.9 \%$, had average grain sizes of $30 \mu \mathrm{m}$ and $50 \mu \mathrm{m}$ respectively, randomly distributed. For the Ti-30Mo, samples of 60 and $180 \mu \mathrm{m}$ grain size in a random orientation were used. Cathodic charging in a Teflon cell was done from a solution of 5 vol. $\% \mathrm{H}_{2} \mathrm{SO}_{4}$ at constant current densities between 3 and 
$30 \mathrm{~mA} \mathrm{~cm}^{-2}$. Charging at a constant potential was also done. Lattice parameter changes during cathodic charging were measured with a Siemens $500 \mathrm{D}$ diffractometer sensitive to $0.002^{\circ}$ in $2 \theta$ and equipped with a copper target. The diffraction peaks were recorded at a scan speed of $0.1 \theta^{\circ} \mathrm{min}^{-1}$. The peak position was determined at its halfwidth relative to the maximum X-ray intensity. Small changes in peak shape did not affect the determination of the peak position.

Hydrogen permeation experiments were also done to characterize the X-ray diffraction results better. The permeation technique is known to be sensitive to very small amounts of hydrogen but demands a careful preparation of the samples. An important consideration is the surface treatment of the sample, particularly at the far side. An anodic potential is applied at the exit surface to ionize the hydrogen atoms arriving at this surface. To avoid passivation of the metal at the applied potential, its surface was coated by r.f. sputtering with $150 \mathrm{~nm}$ of palladium on both sides. The electrolyte used was a precleaned and deaerated solution of $0.1 \mathrm{~N} \mathrm{NaOH}$. An anodic potential of $-50 \mathrm{mV}$ with respect to a saturated calomel electrode (SCE) was applied at the anodic compartment, and argon purging was continued during permeation. On the entry side the charging was done at constant current densities. Ti-30Mo samples were prepared for transmission electron microscopy (TEM) examination before and after charging. The hydrogen contents after cathodic charging at different current densities and times was measured by hot-vacuum extraction. The average concentration profiles along the diffusion direction were determined by analysis of sections of Ti-30Mo rod samples $50 \mu \mathrm{m}$ thick. Because of the very high solubility of hydrogen in Ti-30Mo, most of the work was done with this alloy.

\section{RESULTS}

Three important anomalies were found during the cathodic charging of $\mathrm{Ti}-30 \mathrm{Mo}$, tantalum and niobium: (a) much slower kinetics of the lattice parameter change compared with those expected from diffusion-controlled kinetics, (b) a non-uniform lattice parameter change, depending on grain orientation, and (c) a change in the angle of diffraction, suggesting grain rotation. Calculations based on normal hydrogen diffusion indicate that the hydrogen atoms should arrive at the far side in less than $5 \mathrm{~min}$ and that, on continuous charging, no further change in lattice parameter is expected after charging for about $2 \mathrm{~h}$. However, lattice parameter changes were observed for as long as the charging was maintained, which in some cases exceeded $30 \mathrm{~h}$ (Fig. 1). A uniform lattice parameter is usually expected for all the grains at a given distance along the diffusion path regardless of their orientation. However, Fig. 1 shows that the lattice parameter changes obtained from the various diffracting planes are different. The relative values of the lattice parameter changes obtained from the various diffraction planes during charging were in general erratic. In some runs, one of the diffraction planes, e.g. (200), gave the largest change from the beginning of the charging but, in other experiments, it gave the smallest change. Furthermore, in a few cases, periods of constant lattice parameter were observed for one of the diffracting orientations while the others showed continuous increases in lattice parameter. Another anomaly observed was a change in the angle of diffraction which increased with increase in the magnitude of the lattice expansion caused by hydrogen charging. The observed anomalies were not an effect of hydride precipitation since no additional diffraction peaks were detected at both sides of the samples during and after charging. This was confirmed by TEM examination of the charged samples.

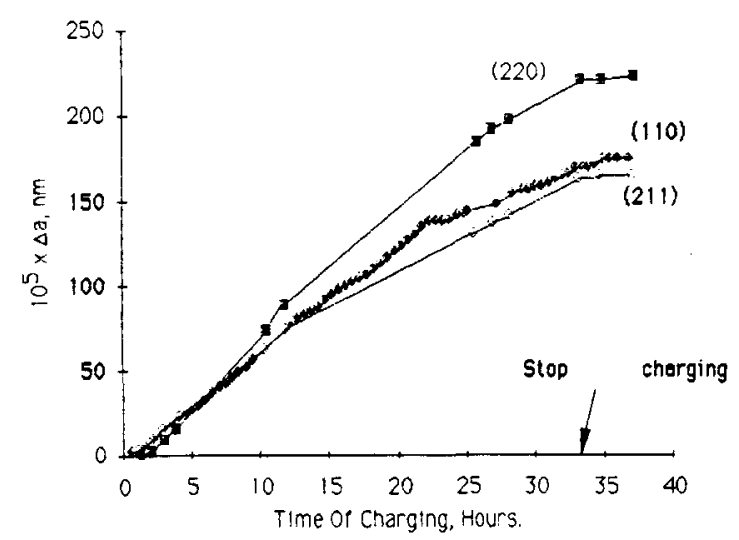

Fig. 1. Lattice parameter change in a $\mathrm{Ti}-30 \mathrm{Mo}$ plate of $60 \mu \mathrm{m}$ grain size during hydrogen charging at 25 $\mathrm{mA} \mathrm{cm} \mathrm{cm}^{-2}$ in $5 \% \mathrm{H}_{2} \mathrm{SO}_{4}$. 
Hydrides were detected in $\mathrm{Ti}-30 \mathrm{Mo}$ only when the charging produced concentrations greater than 10000 wt.ppm.

Samples of approximately the same thicknesses but of different grain sizes behaved differently when hydrogen charged. Considerably faster changes in lattice parameter were observed in the larger-grained samples than in the smaller-grained samples, particularly during charging in the first few hours (Fig. 2). The charging of samples of approximately the same grain sizes but of different thicknesses resulted in larger lattice parameter changes in the thinner samples. The finding of slower changes in lattice parameter for samples of large grain boundary area indicates that grain boundary diffusion, which is sometimes considered to be faster than lattice diffusion, is not playing a role. Hydrogen charging done at constant potentials rather than at constant currents gave similar results. However, the condition of the sample before charging affected the diffusion process. Thus, when niobium samples were charged in the airquenched condition, only very slight changes in lattice parameter at the far side were detected after about $10 \mathrm{~h}$, probably because of the presence of quench-induced dislocations. In well-annealed samples the lattice parameter change at the far side was large and was detected in less than 15 min.

Figure 3 shows the hydrogen concentration profiles of two samples after cathodic charging at $25 \mathrm{~mA} \mathrm{~cm}^{-2}$ for $4 \mathrm{~h}$ and $35 \mathrm{~h}$ respectively. Each point on the figure is the average hyd-

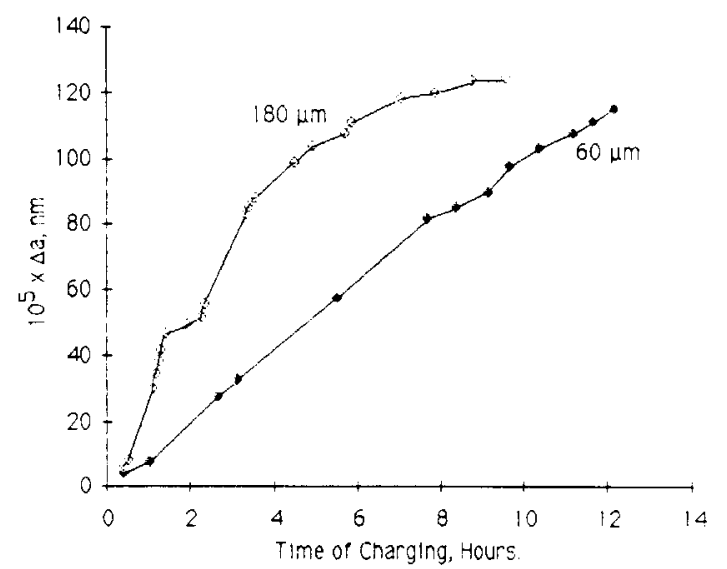

Fig. 2. Influence of grain size on the lattice parameter change of $\mathrm{Ti}-30 \mathrm{Mo}, 450 \mu \mathrm{m}$ thick, during hydrogen charging at $25 \mathrm{~mA} \mathrm{~cm}$. rogen concentration over a distance of about $75 \mu \mathrm{m}$ along the diffusion direction. Peaks of high hydrogen content are seen near the entry and far sides of the sample charged for $35 \mathrm{~h}$, whereas the sample charged for $4 \mathrm{~h}$ shows regions of high hydrogen content mostly near the entry side. Samples charged at lower charging current densities showed much lower numbers of these regions. It is evident that regions of localized hydrogen accumulation increased with increasing time of charging and with increasing charging current density.

To identify the defects introduced by cathodic charging, thin films of $\mathrm{Ti}-30 \mathrm{Mo}$ were prepared with a jet polisher for TEM examination. Thinning was done from both sides of the diffusion specimens, so that the microstructure investigated lies at a position about half-way between the entry and far sides. The dislocation density found for the charged samples was considerably higher than that for the annealed samples which showed a density of about $10^{8} \mathrm{~cm}^{-2}$. Dislocations were found to be distributed at random, in clusters and in networks. The left-hand side of Fig. 4 shows a large cluster of dislocations in which the density can be as much as 1000 times that in an annealed sample. This resembles the clusters of dislocations found in nickel [6] after diffusion of carbon. An important observation is the presence of dislocation pile-ups at grain boundaries, as can be seen at the upper left in Fig. 5 where the spacing of the dislocations is irregular. The piling-up of dislocations at barriers (Figs. 5 and 6 ) is commonly found in

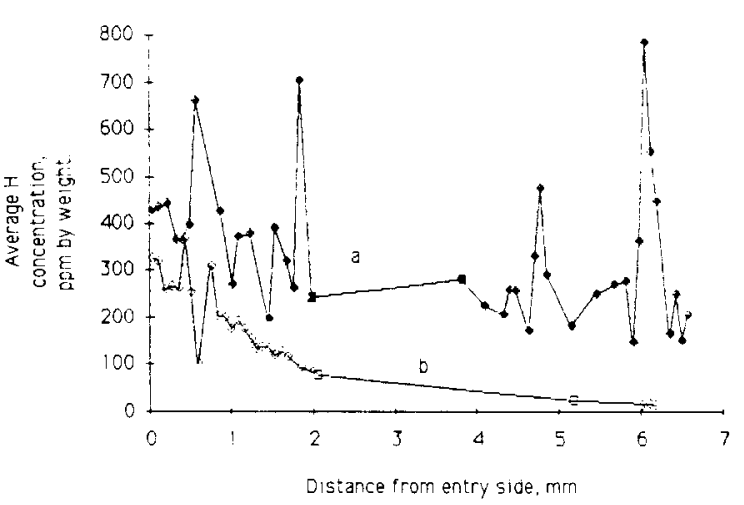

Fig. 3. Average hydrogen concentration profile in $\mathrm{Ti}-30 \mathrm{Mo}$ after charging at $25 \mathrm{~mA} \mathrm{~cm} \mathrm{~cm}^{-2}$ for $35 \mathrm{~h}$ (curve a) and $4 \mathrm{~h}$ (curve b). Each point is the concentration measured over a distance of $75 \mu \mathrm{m}$ within the sample. No data are available between the points. 


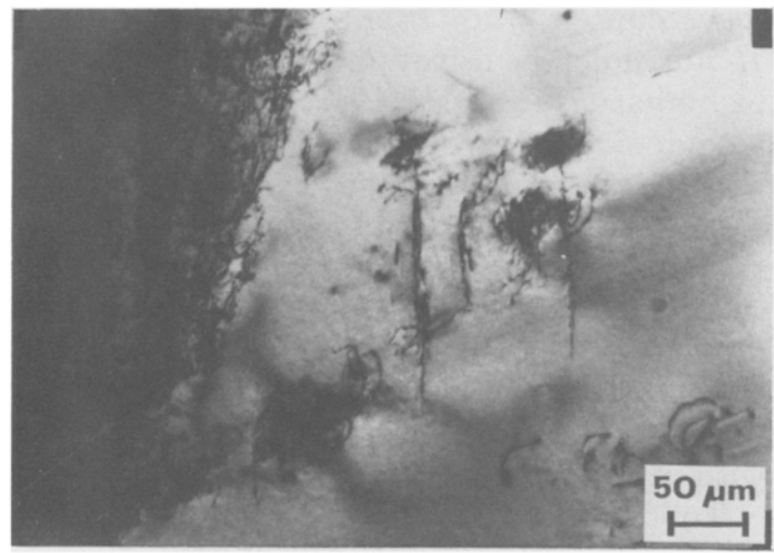

Fig. 4. TEM micrograph showing clusters of dislocations in a $\mathrm{Ti}-30 \mathrm{Mo}$ plate after charging at $25 \mathrm{~mA}$ $\mathrm{cm}^{-2}$ in $5 \% \mathrm{H}_{2} \mathrm{SO}_{4}$ for $6 \mathrm{~h}$. (Magnification, $50000 \mathrm{x}$.)

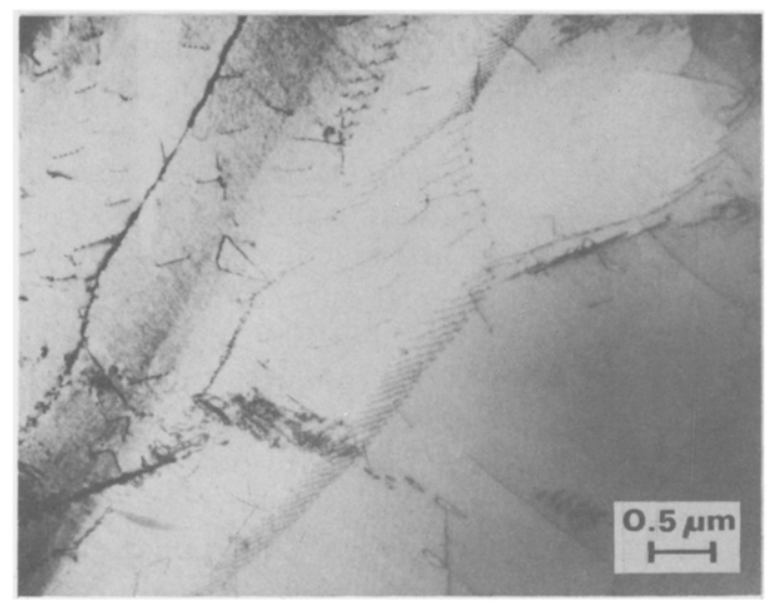

Fig. 5. TEM micrograph of a Ti-30Mo plate after charging at $3 \mathrm{~mA} \mathrm{~cm}^{-2}$ in $5 \% \mathrm{H}_{2} \mathrm{SO}_{4}$ for $2 \mathrm{~h}$. The pile-up of dislocations at a grain boundary on the left-hand side of the picture should be noted. (Magnification, $20000 \times$.)

metals deformed by application of external forces. Finding pile-ups in hydrogen-charged samples leads to the inference that the charging itself develops large enough stresses to generate dislocations, which then move towards the far side and pile up at grain boundaries. Dislocation arrangements near the far side were identified by thinning from the entry side while maintaining the far side coated with Stop Off Lacquer, a commercial acid-resistant varnish. Figure 7 shows the dislocation arrangement at the far side of a Ti-30Mo sample charged in $5 \% \mathrm{H}_{2} \mathrm{SO}_{4}$ for $2 \mathrm{~h}$ at $3 \mathrm{~mA} \mathrm{~cm} \mathrm{~cm}^{-2}$. We notice that most of the dislocations are found along slip planes, in accord to similar

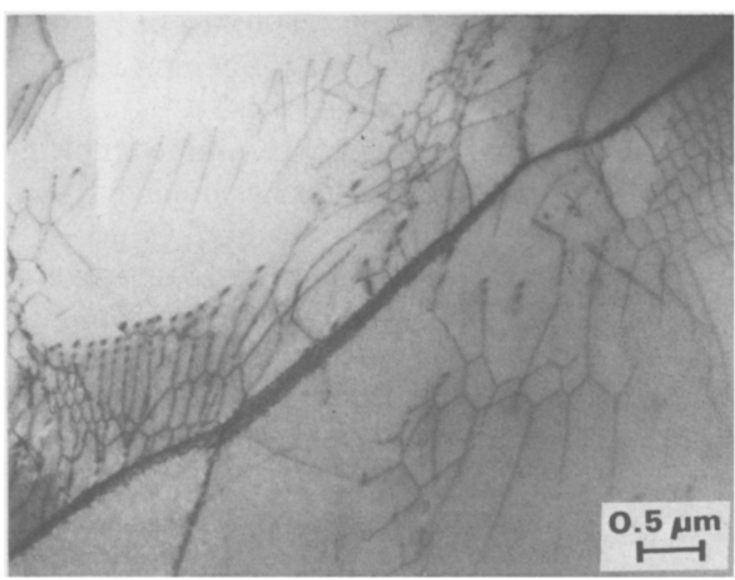

Fig. 6. TEM micrograph from the same sample as in Fig. 5, showing a network of dislocations near a grain boundary. (Magnification, $20000 \times$.)

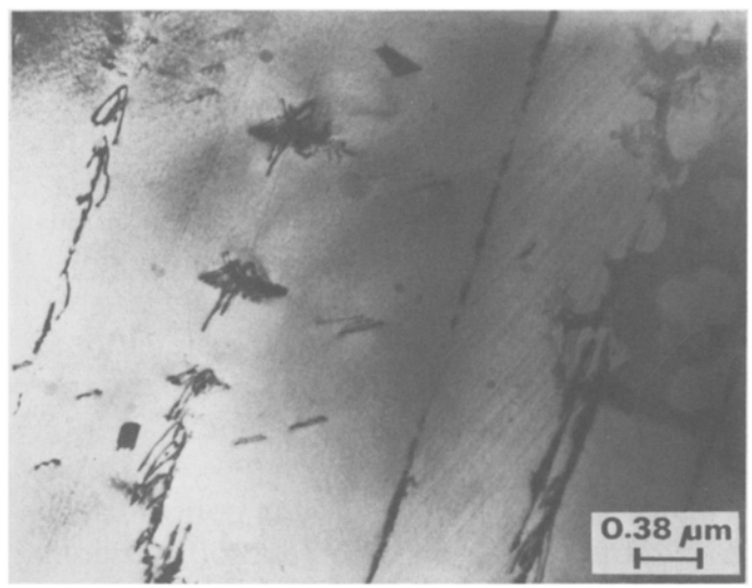

Fig. 7. TEM micrograph of a $\mathrm{Ti}^{-30 \mathrm{Mo}}$ plate at its far side (away from the hydrogen entry side) after charging at $3 \mathrm{~mA} \mathrm{~cm}^{-2}$ in $5 \% \mathrm{H}_{2} \mathrm{SO}_{4}$ for $2 \mathrm{~h}$. Most of the dislocations are seen to be at slip planes. (Magnification, $26000 \times$.)

findings in other systems after interstitial diffusion [7].

Scanning and optical microscopy done on charged Ti-30Mo plates revealed other defects produced by hydrogen charging. Figure 8 shows a deformation band and cracks at the far surface of a charged sample after polishing and etching. Deformation bands may have been formed as a result of accumulations of edge dislocations of the same sign on slip planes. Their formation in polycrystalline specimens during deformation is known to be facilitated by the restraints imposed by grain boundaries. Another defect shown in Fig. 8 is 


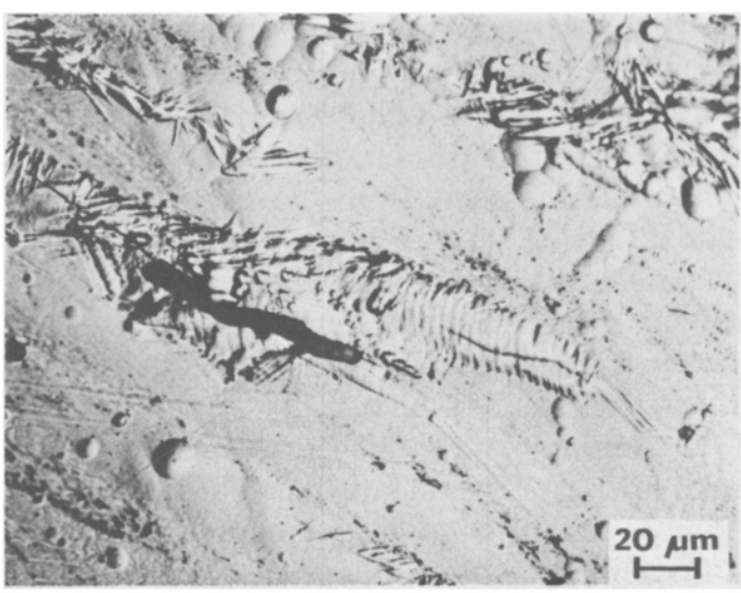

Fig. 8. Microstructure taken at the far surface of a Ti-30Mo plate after charging in $0.1 \mathrm{~N} \mathrm{NaOH}$ at $8 \mathrm{~mA}$ $\mathrm{cm}^{-2}$ for $5 \mathrm{~h}$. The picture shows deformation bands and cracks. (Magnification, $500 \times$.)

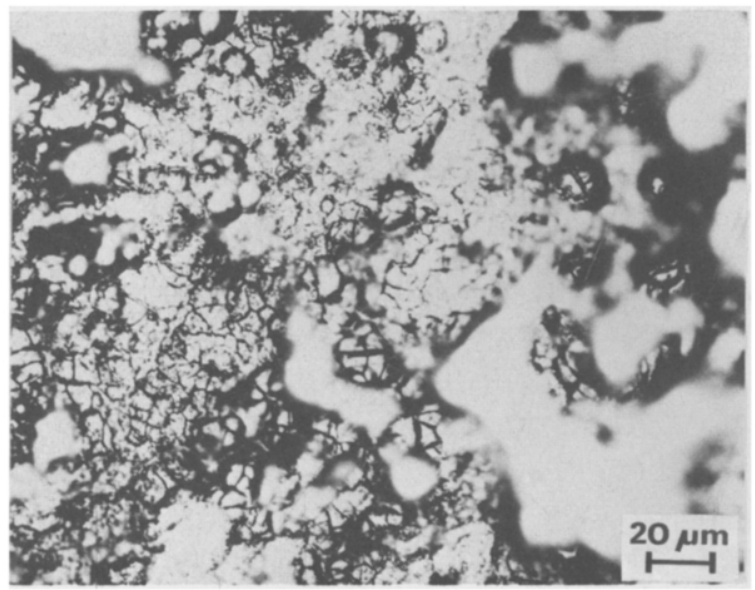

Fig. 9. Microstructure of a $\mathrm{Ti}-30 \mathrm{Mo}$ plate at its far surface after charging at $3 \mathrm{~mA} \mathrm{~cm}^{-2}$ for $2.25 \mathrm{~h}$. The picture shows subgrains about $5 \mu \mathrm{m}$ in size. (Magnification, $500 \times$.)

surface rumpling in the form of circular markings. These formations appeared to a greater extent at the entry surface. Cathodic charging resulted also in the formation of subgrains at both sides of the plates (Fig. 9). In the tantalum and niobium samples, surface rumpling was the most abundant defect found, being more severe at the entry than at the far surface. No TEM work was done on these samples.

The anomalies observed during cathodic charging were also studied by hydrogen permeation experiments. When hydrogen diffuses in a metal of constant defect population, the permeation rate increases smoothly towards a steady state. However, if the diffusion of



Fig. 10. Change in hydrogen permeation current in $\mathrm{Ti}^{-} 30 \mathrm{Mo}, 440 \mu \mathrm{m}$ thick, charged at $2 \mathrm{~mA} \mathrm{~cm}^{-2}$ in $0.1 \mathrm{~N} \mathrm{NaOH}$.



Fig. 11. Change in hydrogen permeation current in $\mathrm{Ti}-30 \mathrm{Mo}, 550 \mu \mathrm{m}$ thick, charged at $8 \mathrm{~mA} \mathrm{~cm}^{-2}$ in $0.1 \mathrm{~N} \mathrm{NaOH}$.

hydrogen is affected by continuously generated lattice defects, the permeation cannot follow that simple pattern. The permeation curves of $\mathrm{Ti}-30 \mathrm{Mo}$, tantalum or niobium charged at relatively high current densities are expected to lack a steady state permeation, since the diffraction experiments revealed that a constant lattice parameter is not reached. For these metals, calculations for fickian diffusion indicate that a steady state hydrogen permeation flux is expected to be attained in less than $10 \mathrm{~min}$.

A typical permeation curve obtained with a Ti-30Mo sample, $440 \mu \mathrm{m}$ thick, charged at $2 \mathrm{~mA} \mathrm{~cm}^{-2}$ can be seen in Fig. 10. There are anomalous changes in permeation current during charging throughout the duration of the experiment. No steady state permeation flux is attained. At higher charging current 
densities the permeation current increases continuously until the sample spontaneously fractures through its thickness (Fig. 11). The time at which the sample experiences fracture is marked by a sudden jump in permeation current. Cracking of the sample associated with jumps in permeation currents has also been observed in $\beta-\mathrm{Ti}$ [15]. Prolonged charging also causes plastic deformation and curving of the sample concave towards the far side. The curvature may be removed by annealing at $550{ }^{\circ} \mathrm{C}$ for $30 \mathrm{~min}$. Also, extensive slip lines at both the entry and the far sides are noticed.

\section{DISCUSSION}

\subsection{Stresses developed due to hydrogen con- centration gradients}

Hydrogen charging establishes a concentration gradient and also a stress gradient within the metal plate. A time-dependent stress equation due to hydrogen diffusion can be derived in analogy to the solute diffusion treated by Prussin [2] and $\mathrm{Li}$ [16] following the work of Timoshenko [17] on stresses arising from temperature gradients. These researchers considered solute diffusion from two sides of a plate. This mode of charging establishes a solute concentration profile which is symmetric with respect to the middle section of the plate. In the present work, hydrogen charging occurs only from one side of a metal plate, and a zero flux of hydrogen at the far side of the plate may be assumed because of the air-formed oxide film there $[18,19]$. Hence the hydrogen concentration profile is non-symmetric with respect to the midplane of the sample, and this must be taken into account in the derivation of the stress equation. The equation derived by $\mathrm{Li}$ can be applied to the present case with the addition of a term needed to superpose bending stresses due to non-symmetric hydrogen distribution within the plate. With this consideration, the stresses developed in the $y$ and $z$ directions are equal and are given by

$$
\begin{aligned}
\sigma= & -\frac{V E C}{3(1-\nu)}+\frac{V E}{6 L(1-\nu)} \int_{0}^{L} C \mathrm{~d} x \\
& +\frac{V E}{2 L^{3}(1-\nu)} \int_{0}^{L} C x^{2} \mathrm{~d} x
\end{aligned}
$$

The first term represents the compressive stress arising from the strain due to the concentration gradient. The second term is a uniform tension superposed such that the resultant of the normal forces over the cross-section of the plate is zero. The third term represents the stress relief by bending. The stress equation shown above is given in terms of $C(x)$ which describes the hydrogen concentration profile at a specific time of charging.

The expression for the time dependence of the hydrogen concentration can be derived by solving Fick's second law of diffusion with the boundary conditions established by the mode of charging and with the assumption that the plate is free of defects. If it is considered that the entry of hydrogen occurs at a constant hydrogen concentration $C_{s}$ at $x=0$, the time-dependent concentration equation is

$$
\begin{aligned}
C(x, t)= & C_{\mathrm{s}}-\sum_{n=0}^{\infty} \frac{4 C_{\mathrm{s}}}{(2 n+1)} \sin \left\{\frac{(2 n+1) \pi x}{2 L}\right\} \\
& \times \exp \left\{\frac{-(2 n+1)^{2} \pi^{2} D t}{4 L^{2}}\right\}
\end{aligned}
$$

when eqn. (2) is substituted into eqn. (1), the stress equation becomes

$$
\begin{aligned}
\sigma= & \frac{2 V E C_{s}}{3(1-\nu)} \sum_{n=0}^{\infty} \frac{\exp \left(-\rho_{n}^{2} D t / L^{2}\right)}{\rho_{n}} \\
& \times\left\{\sin \left(\frac{\rho_{n} x}{L}\right)-\frac{1}{2 \rho_{n}}-\frac{3}{\rho_{n}{ }^{2}} \sin \rho_{n}+\frac{3}{\rho_{n}{ }^{3}}\right\}
\end{aligned}
$$

where $\rho_{n}=(2 n+1) \pi / 2, L$ is the plate thickness, $E$ is Young's modulus, $\nu$ Poisson's ratio, $V$ the partial molal volume of hydrogen and $D$ the normal lattice diffusivity of hydrogen. These equations neglect the contribution of stress gradient to the driving force for diffusion.

Figure 12 shows the stress profile that would be developed within a plate $500 \mu \mathrm{m}$ thick by hydrogen diffusion in the absence of dislocation generation. The hydrogen diffusivity was assumed to be $1 \times 10^{-6} \mathrm{~cm}^{2} \mathrm{~s}^{-1}$ [20]. The expansion caused by hydrogen charging at the near-entry region places that region in compression because of the constraint by the underlying unexpanded hydrogen-free metal. It is seen that the maximum compressive stresses at the entry side are de- 


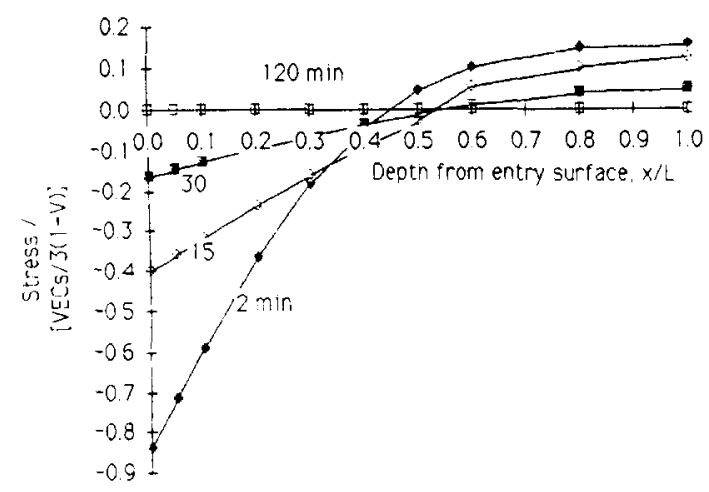

Fig. 12. Stress profile developed during hydrogen diffusion in a plate $500 \mu \mathrm{m}$ thick. The assumed diffusivity of hydrogen is $10^{-6} \mathrm{~cm}^{2} \mathrm{~s}^{-1}$.

veloped at the initiation of charging and are given by

$\sigma_{\mathrm{s}}=-\frac{V E C_{\mathrm{s}}}{3(1-\nu)}$

Using a typical value of $1.8 \times 10^{-3} \mathrm{~nm}$ for the change in lattice parameter measured at the far side of Ti-30Mo and assuming that this is due to lattice-dissolved hydrogen, we find that the corresponding concentration of hydrogen is about $2000 \mathrm{wt} . \mathrm{ppm}$. When this value is substituted in eqn. (4), $8.6 \times 10^{8} \mathrm{~Pa}$ is calculated as the initial stress that would be developed in the absence of dislocation generation. The corresponding maximum shear stress, $4.3 \times 10^{8} \mathrm{~Pa}$, is comparable with the yield stress of the material, $7.8 \times 10^{8} \mathrm{~Pa}$, and therefore dislocations are expected to be generated. The stress at the entry side must be much greater than the value given above because the concentration of dissolved hydrogen at the entry side is larger than that at the far side of the plate.

\subsection{Time-dependent effects during charging}

In both the X-ray diffraction and the permeation measurements a steady state is not reached in a time much larger than that calculated for fickian diffusion. This can be explained only by the generation of dislocations and by the trapping of hydrogen at the dislocations both of which continue through the duration of the experiment. The steep hydrogen concentration gradient at the input surface, which is responsible for the genera- tion of dislocations, is maintained by the immediate trapping of the injected hydrogen. The trapped hydrogen is moved away from the input surface by the dislocations which are caused to glide by the shear stress at the input region. As the dislocation-conveyed hydrogen moves towards the far surface, it is distributed to grain boundaries, to dislocation pile-ups at barriers and to grain interiors. Hydrogen dissolved in the grain interiors, i.e. not adsorbed on grain boundaries or on dislocations, is responsible for the change in lattice parameter that is measured by X-ray diffraction, but a contribution thereto from dislocation-held hydrogen cannot be ruled out. However, the main contribution to the measured hydrogen content (Fig. 3 ) is that from trapped hydrogen. The maximum change in lattice parameter at the far side of $\mathrm{Ti}-30 \mathrm{Mo}$ alloy, the data for which are shown in Fig. 3, is $2 \times 10^{-4} \mathrm{~nm}$ and, with the known partial molal volume of hydrogen in this alloy of $1.39 \mathrm{~cm}^{3} \mathrm{~mol}^{-1}$ [21], the lattice-dissolved hydrogen is calculated to be 220 wt.ppm compared with the larger values shown in Fig. 3.

As the dislocations move away from the input side, they interact with each other and with grain boundaries, becoming annihilated, forming pile-ups and subsequently breaking through, or causing changes in grain boundary configuration; all these effects depend on the orientation and type of grain boundary. In addition, the adsorption of hydrogen on the grain boundaries is a function also of the orientation and type of grain boundary [22]. For these reasons, it should be expected that the distribution of the hydrogen, conveyed either by diffusion or by dislocation transport, between the lattice of a grain and its boundary is a function of the grain orientation. Thus the heterogeneity of the lattice parameters, and hence the non-uniformity of concentration of lattice-held hydrogen that is observed, can be qualitatively understood. In addition, a sample of smaller grain size has a larger grain boundary area at which the conveyed hydrogen can be trapped, compared with a sample of larger grain size. Hence, in the former a smaller amount of lattice-dissolved hydrogen should be expected to result from the sharing of conveyed hydrogen between grain boundary and lattice, which is what is observed.

The formation of subgrains can be expected to occur as a result of the tendency of the 
newly generated dislocations to develop a configuration of low energy [23]. The TEM results suggest that the generated dislocations move along slip planes and pile up at grain boundaries. In the region of the pile-up, high stresses are likely to develop such that breakdown of the barrier will generate more dislocations in the adjoining grain. The disparity of lattice parameter changes found in grains of different orientations implies that the grains expand by different amounts. The non-uniform expansion of the grains can be accommodated if they slide or rotate with respect to each other, causing a change in the angle of diffraction. Some grains lose the proper orientation for diffraction and others are placed into orientation for diffraction. The $\mathrm{X}$-ray diffraction intensity then changes, since it is dependent on the number of grains diffracting together [24]. To accommodate the sliding of groups of grains without creating voids, secondary effects such as emersion of grains at a free surface may occur [25]. In accord with these expectations, round protruberances have been observed on the surface of charged samples in sizes ranging from 0.1 to $60 \mu \mathrm{m}$ in diameter (Fig. 13). However, more detailed experimentation and analysis are necessary to understand this aspect better.

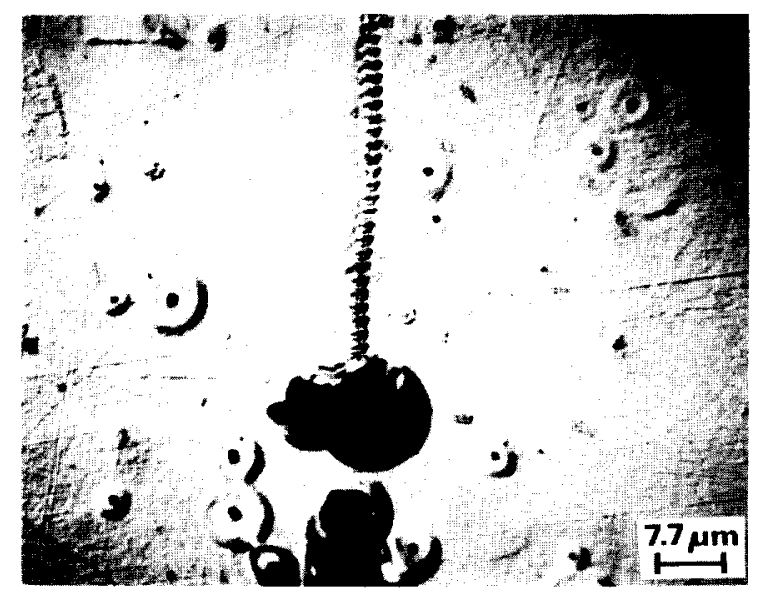

Fig. 13. Microstructure of the hydrogen entry surface of $\mathrm{Ti}-30 \mathrm{Mo}$ after charging at $25 \mathrm{~mA} \mathrm{~cm}^{-2}$ in $5 \%$ $\mathrm{H}_{2} \mathrm{SO}_{4}$ for $20 \mathrm{~h}$. It should be noted that the round protruberances are distributed randomly; a deformation band should also be noted. (Magnification, 1300 $x$.)

\subsection{Critical hydrogen concentration to avoid defect generation}

There should exist a threshold charging current below which normal permeation transients can be obtained, at a value such that the hydrogen concentration and gradient cannot generate sufficient stress for dislocation production. However, it was not possible to determine the threshold charging current density because charging in the low current density regime gave abnormal transients, probably because of surface barriers which are known to develop in these conditions during charging in liquid media [26]. However, approximations can be made, taking into consideration the fact that cathodic charging in $5 \% \mathrm{H}_{2} \mathrm{SO}_{4}$ at currents at and above $100 \mu \mathrm{A} \mathrm{cm}^{-2}$ resulted in the formation of surface rumpling at both the entry and the far sides, probably because of dislocation generation during charging. It can be assumed that the anodic current in $\mathrm{Ti}-30 \mathrm{Mo}$ is only slightly smaller than the input charging current, as is the case in palladium in which the anodic current is $94 \%$ of the input charging current. Thus a value of approximately $94 \mu \mathrm{A} \mathrm{cm}^{-2}$ can be taken as the permeation current corresponding to a charging current of $100 \mu \mathrm{A} \mathrm{cm}^{-2}$. With this value, the atomic concentration ratio for hydrogen dissolved in Ti-30Mo at the entry surface can be calculated from $\eta=J L A / D F \delta$ where $J$ is the steady state permeation current density, $L$ the sample thickness, $A$ the atomic weight, $F$ Faraday's constant, $\delta$ the density of the metal and $\eta$ the atomic concentration ratio. Thus, it is found that the threshold input subsurface hydrogen concentration ratio in $\mathrm{Ti}$ $30 \mathrm{Mo}$ is about $3.7 \times 10^{-4}$. The corresponding compressive stress just below the entry surface estimated from eqn. (4) is found to be $2.3 \times$ $10^{6} \mathrm{~Pa}$. This is a relatively low value of stress. Therefore, there may exist dislocation sources initially present near the entry surface which aid in the generation of dislocations at low levels of stress, or there may exist large localized hydrogen concentrations associated with grain boundaries which produce large local stresses (we are grateful to the reviewer of this paper for the suggestion of this possibility). An alternative explanation may be the diffusion-induced dislocation glide mechanism originally suggested by Shewmon et al. [27] and recently espoused by Li et al. [28]. How- 
ever, this mechanism depends on the fact that the diffusivity of hydrogen along dislocations and grain boundaries is much greater than in the lattice, a point which has not been proven for the b.c.c. metals in which hydrogen diffuses with great rapidity.

\section{CONCLUSIONS}

(1) Cathodic charging of Ti-30Mo plates above a certain current density results in a continuous generation of dislocations at the input surface and in their emission towards the far side. The generated dislocations serve as traps and as carriers of hydrogen atoms across the metal thickness. Tantalum and niobium have also given indication of abnormal hydrogen permeation, the cause of which is believed to be of the same character as that found in $\mathrm{Ti}-30 \mathrm{Mo}$.

(2) The defect generation is a result of stresses due to hydrogen concentration gradients produced at the entry surface by the charging. An estimation of the critical stress corresponding to the charging current density above which defects can be observed gives a value of approximately $2 \times 10^{6} \mathrm{~Pa}$. This low value suggests that dislocation sources are initially present near the entry surface.

(3) The newly generated dislocations are found to form various arrangements. Clusters of dislocations of various densities are found in different locations. The majority of the dislocations appear along slip planes. Also the generated dislocations form subgrains at both the entry and the far sides of the charged plates.

(4) Disparity in lattice parameter changes on grains oriented differently occurs during charging. This is a result of inhomogeneous distribution of the generated dislocations in any one grain which compete with the lattice for the hydrogen transported in to that grain. The non-homogeneous expansion of the grains causes a relative rotation of some grains with respect to others. As a consequence, some grains change their orientation, and a change in the angle of diffraction occurs.

(5) Samples of small grain boundary area show large changes in lattice parameter in comparison with samples of large grain boundary area. This is a result of lesser competition from grain boundaries in sharing the transported hydrogen in the former compared with the latter case.

(6) The condition of the sample before charging is a determining factor for the magnitude of the lattice parameter change observed during charging.

\section{ACKNOWLEDGMENT}

This research was supported by the U.S. Department of Energy, Office of Basic Energy Sciences, under Contract DOE/DE-FG0284 ER 45173.

\section{REFERENCES}

1 M. E. Armacanqui and R. A. Oriani, Corrosion, 41 (1985) 287.

2 S. Prussin, J. Appl. Phys., 32 (1961) 1876.

3 P. S. Ayres and P. G. Winchell, J. Appl. Phys., 39 (1968) 4820.

4 P. S. Ayres and P. G. Winchell, J. Appl. Phys., 43 (1972) 816.

5 T. Sakuma, K. Yamasaki and T. Nishizawa, Scr. Metall., 10 (1976) 687.

6 J. K. Boah and P. G. Winchell, Metall. Trans. A, 6 (1975) 717.

7 T. Sakuma, S. Takada, M. Hasabe and T. Nishizawa, Trans. Jpn. Inst. Met., 17 (1976) 637.

8 S. D. Kapusta, T. T. Kam and K. E. Heusler, $Z$. Phys. Chem., Frankfurt-am-Main, 123 (1980) 219.

9 J. O'M. Bockris and P. K. Subramanyan, Electrochim. Acta, 16 (1971) 2169.

10 J. O'M. Bockris and P. K. Subramanyan, Corros. Sci. 10 (1970) 435.

11 J. Flis and A. Janko, Acad. Polon. Sci., Ser. Sci. Chim., 12 (1964) 51.

12 K. N. Akhurst and P. H. Pumphrey, Proc. 2nd Int. Congr. on Hydrogen in Metals, Paris, 1977, International Association for Hydrogen Energy, Pergamon, Oxford, 1978, p. 3B1.

13 S. X. Xie and J. P. Hirth, Corrosion, 38 (1982) 487.

14 J. L. Lee and J. Y. Lee, Metall. Trans. A, 16 (1985) 468.

15 J. J. Delucia, Electrolytic hydrogen in beta titanium, NTIS Rep. AD-A028496, 1976, p. 129 (National Technical Information Service).

16 J. C. M. Li, Metall. Trans. A, 9 (1978) 1353.

17 S. Timoshenko, Theory of Elasticity, McGrawHill, New York, 1934, p. 209.

18 J. O'M. Bockris, M. A. Genshaw and M. Fullerwider, Electrochim. Acta, 15 (1970) 47.

19 M. Kanno, M. Yamawaki and T. Namba, Proc. 2nd JIM Int. Symp. on Hydrogen in Metals, 
Minakani, 1979, in Trans. Jpn. Inst. Met., Suppl., 21 (1980) 105.

20 P. N. Adler, R. L. Schulte, E. J. Scheneid, E. A. Kamykowski and F. J. Kuehne, Metall. Trans. A, 11 (1980) 1617 .

21 W. W. Gerberich, N. R. Moody, C. L. Jensen, C. Hayman and K. Jatavallabhula, in I. M. Bernstein and A. W. Thompson (eds.), Proc. Int. Conf. on Hydrogen Effects in Metals, Moran, 1980, Metallurgical Society of AIME, Warrendale, PA, 1981, pp. 731-744.

22 T. Asaoka, G. Lapasset, M. Aucouturier and P.
Lacombe, Corrosion, 35 (1979) 378.

23 P. G. Winchell, J. Boah and P. S. Ayres, J. Appl. Phys., 42 (1971) 2612.

24 J. W. Jeferry, Methods in X-ray Crystallography, Academic Press, London, 1971.

25 R. C. Gifkins, J. Mater. Sci., 13 (1978) 1926.

26 J. S. L. Leach and R. J. Saunders, J. Electrochem. Soc., 113 (1966) 681,

27 P. G. Shewmon, G. Meyrick, S. Mishra and T. A. Parthasarathy, Scr. Metall., 17 (1983) 1231.

28 J. C. M. Li, C. G. Park and S. M. Ohr, Scr. Metall., 20 (1986) 371. 